\title{
Entrevista com o professor e pesquisador Luiz Marques (Unicamp)
}

An interview with professor and researcher Luiz Marques (Unicamp)

\section{Luiz Marques}

É professor do Departamento de História da IFCH-Unicamp. Publicou diversos livros e ensaios sobre a Tradição Clássica e, mais recentemente, também sobre a crescente degradação antropogênica dos ecossistemas, entre os quais o livro "Capitalismo e Colapso Ambiental" (Editora Unicamp).

\section{Entrevista por Lucas Murari}

Doutor em Comunicação e Cultura pela Escola de Comunicação da Universidade Federal do Rio de Janeiro, com período sanduíche na Université Sorbonne Nouvelle - Paris 3 (bolsa CAPES). É editor-executivo da Revista Eco-Pós (UFRJ). Atualmente realiza estágio de pós-doutorado na ECO/UFRJ (bolsa CAPES).

REVISTA ECO-PÓS: Sua publicação "Capitalismo e Colapso Ambiental" (Editora Unicamp) foi lançado originalmente em 2015. Quais mudanças significativas se deram nesse relativo curto intervalo de tempo?

Luiz Marques: 0 que acima de tudo define nossos dias é a aceleração da degradação socioambiental do planeta. Essa degradação é multiforme e sistêmica. Seus aspectos mais salientes são a crescente desestabilização do sistema climático, a aniquilação da biodiversidade, o aumento asfixiante da poluição e da intoxicação química dos organismos, a piora das condições sanitárias, o abismo crescente da desigualdade socioeconômica, surtos imprevistos de negacionismo, de irracionalismo e de obscurantismo de extrema-direita. Esses aspectos estão interligados e configuram o que se poderia chamar a Grande Regressão. Sua velocidade é vertiginosa. 0 mundo tal como

\section{Dossiê O Pensamento Ecológico - https://revistaecopos.eco.ufri.br/}

ISSN 2175-8689 - v. 23, n. 2, 2020

DOI: 10.29146/eco-pos.v23i2.27632 
se afigura neste final de 2020 é já muito diverso daquele longínquo mundo de setembro de 2015, quando se lançou a primeira edição do livro. Em 2016 e 2018, a segunda e a terceira edições do livro já tentavam mostrar essa distância crescente, e a edição inglesa de 2020 (Springer) nos projeta em um mundo ainda mais distante e sempre muito pior. É claro que há alguns pontos positivos a ressaltar no balanço desses cinco anos, sendo os mais importantes a muito maior consciência da gravidade extrema da situação em que se encontram as sociedades contemporâneas, o fortalecimento dos movimentos socioambientais e as diversas iniciativas de líderes globais de grande lucidez, como Antônio Guterres, secretário-geral da ONU, e o papa Francisco, a começar por sua encíclica Laudato si', publicada em junho de 2015, quando o livro já estava em gráfica. É de agosto de 2018 o início das greves de Greta Thunberg em frente do Parlamento sueco, estopim das greves globais dos jovens pelo clima. Entre maio e outubro de 2018 teve início o movimento Extinction Rebellion no Reino Unido. No hemisfério sul, e em especial na América Latina, as coisas começam também a se mover e um bom exemplo disso é a mobilização de vários setores sociais em torno da Assembleia Mundial da Amazônia. No Brasil, movimentos sociais como o MST e o Fórum Popular da Natureza, entre muitos outros, são sinais vitais que tendem doravante a acelerar em sentido socioambiental a agenda ainda anacronicamente "desenvolvimentista" dos partidos progressistas. No âmbito da ciência, fortaleceu-se muito a pesquisa interdisciplinar sobre as crises socioambientais e importantíssimos manifestos assinados por milhares de cientistas vieram à luz desde então. Lembro aqui apenas um: a Advertência dos Cientistas Mundiais à Humanidade: Um Segundo Aviso, de 2017, iniciativa coordenada por William Ripple, da Universidade de Oregon. 0 manifesto, nascido 25 anos após a Eco-92, foi assinado por 15.364 cientistas de 184 países.

Evidentemente, posto que nosso tempo é, como dito, o da Grande Regressão, os retrocessos suplantam de longe os pontos positivos acima elencados. O Acordo de Paris, de dezembro de 2015, o mais importante acordo diplomático da história da ConvençãoQuadro das Nações Unidas sobre as Mudanças Climáticas (UNFCCC, adotada em 1992), está repetindo o mesmo fracasso, de resto previsível, do Protocolo de Kyoto. 0 Acordo entrou em vigor em Novembro de 2016, mas o Irã, o Iraque e a Líbia ainda não o 
ratificaram e a Rússia o ratificou apenas em outubro de 2019. Acrescente-se que os EUA desde logo abandonaram na prática o Acordo, e o que se tem é que ao longo de seus primeiros três anos de vigência (XI/2016 - XI/2019), alguns dos principais países produtores de petróleo e gás natural simplesmente não o reconheceram. As emissões globais de gases de efeito estufa (GEE) aumentaram 0,6\% em 2019 em relação a 2018.0 G20 é responsável por 78\% das emissões globais de $\mathrm{CO}_{2}$ e 15 desses países mais ricos do planeta não estão cumprindo nem suas timidíssimas promessas negociadas em 2015. Em 2019, a China e a Índia aumentaram suas emissões de GEE em 2,6\% e em 1,8\%, respectivamente, em relação a 2018. Nesse mesmo período, segundo dados recentes do Sistema de Estimativa de Emissões de Gases de Efeito Estufa (SEEG), as emissões de GEE no Brasil aumentaram 9,6\%, um aumento assombroso, sendo a sanha piromaníaca e ecocida do agronegócio brasileiro responsável, direta ou indiretamente, por $72 \%$ dos 2,17 bilhões de toneladas de $\mathrm{CO}_{2}$-eq emitidos pelo país no ano passado. Sobretudo após a eleição de Bolsonaro, o Brasil tornou-se um país pária e um dos mais afrontosos exemplos de descumprimento de seus compromissos de Estado. Tenhamos a coragem e a honestidade de dizer alto e bom som que o rei está nu: o Acordo de Paris está hoje na UTI, para não dizer no necrotério. Parece cada vez mais improvável que as próximas COPs o tragam de volta à vida. Situação semelhante é a da Agenda 2030, adotada pela ONU em setembro de 2015, contendo os famosos 17 Objetivos do Desenvolvimento Sustentável. Em 2020, estamos mais distantes de atingir a grande maioria de seus 169 alvos do que estávamos em 2015 e em 2030 estaremos ainda mais distantes do que estamos hoje. Após decênios de progresso em seu combate, a fome mundial, por exemplo, vem aumentando incessantemente. Aumento semelhante se verifica no âmbito das ameaças existenciais a inúmeras espécies de vertebrados e invertebrados. No que se refere ao clima, há uma aceleração vertiginosa das concentrações atmosféricas de GEE e, consequentemente, do aquecimento global. Basta dizer que o aquecimento vinha ocorrendo a uma média de $0,17^{\circ} \mathrm{C}$ por década entre 1970 e 2014 , mas seu ritmo saltou para $0,43^{\circ} \mathrm{C}$ por década entre 2008 e 2017. Em 2015, atingimos $1^{\circ} \mathrm{C}$ no aquecimento médio global superficial, terrestre e marítimo combinados, em relação ao período18801920, período de referência adotado pela NASA. Em 2019, sempre segundo a NASA, 
saltamos para $1,23^{\circ} \mathrm{C}$ !! E 2020 pode apresentar um quadro ainda mais grave, mesmo com o recente La Niña a desacelerar momentaneamente o aquecimento do planeta. Pioras equivalentes acusam-se também nos indicadores de poluição e intoxicação dos organismos. Como afirmava em 2017, a acima mencionada Advertência dos Cientistas Mundiais à Humanidade: "Em breve será tarde demais para mudar o curso de nossa trajetória fracassada e o tempo está se esgotando". Em 2019, outro manifesto coordenado também por William Ripple, afirmava: “Declaramos, com mais de 11.000 signatários cientistas de todo o mundo, de forma clara e inequívoca que o planeta Terra está enfrentando uma emergência climática. (...) A crise climática chegou e está se acelerando mais rápido do que a maioria dos cientistas esperava. É mais grave do que o previsto, ameaçando os ecossistemas naturais e o destino da humanidade". Em 2020, em suma, o futuro que já se insinuava em 2015 escancarou-se definitivamente. Um manifesto publicado em 9 de setembro de 2018 pelo jornal francês Libération ("SOS de 700 Cientistas") começa com este veredito: “Já entramos totalmente no 'futuro climático '"(Nous sommes d'ores et déjà pleinement entrés dans le 'futur climatique ).

REVISTA ECO-PóS: De que forma a Covid-19 se relaciona com os termos chaves presentes no título deste seu livro?

Luiz Marques: A pandemia da covid-19, que em menos de um ano já causou mais de 1,3 milhão de mortes reportadas (o número real é por certo maior), está entrando em sua segunda ou terceira onda e, segundo os gráficos fornecidos diariamente pelo site Worldometers (https://www.worldometers.info/coronavirus/), está agora matando mais que nunca, vale dizer, em torno de 10 mil pessoas por dia. Ela é, contudo, apenas a ponta do iceberg dos impactos crescentes e já inevitáveis que nos confrontarão nos próximos anos. 0 Brasil oferece aqui um caso extremo. Em 8 meses, desde 17 de março deste ano, o país já perdeu cerca de 165 mil vidas, mais de 20 mil mortes por mês, algo como 28 mortes por hora, quase uma morte a cada dois minutos! As perdas brasileiras representam quase $13 \%$ das mortes globais, mas a população do país não chega a 2,8\% da população mundial. A parcela maior de responsabilidade por esse massacre cabe a 
Bolsonaro, que vem assumindo posições até mais extremadamente execráveis que as de Trump em relação à pandemia nos EUA. É imperativo depô-lo da presidência do país, que ele tanto desonra, e julgá-lo ato contínuo por crime contra a humanidade. Que as instituições e os setores mais organizados e mais informados da sociedade brasileira não estejam reagindo à altura dessa monstruosidade, eis algo que mostra o nível de prostração moral ou, se quisermos, de cinismo em que se encontram, sobretudo, os deputados, senadores e os setores econômicos que apoiaram Bolsonaro e continuam a apoiá-lo ou a tolerá-lo, em nome de seu horror quase atávico a tudo o que signifique emancipação popular no Brasil.

Em termos mais gerais, a pandemia nada tem de adventícia. Longe de cair sobre nós como um raio em céu azul, ela foi prevista por um número considerável de cientistas. Em The Coming Plague. Newly Emerging Diseases in a World Out of Balance, Laurie Garrett previu-a claramente e estávamos em 1994! Em 2012, Serge Morand, um ecólogo e biólogo do CNRS, na França, escreveu um livro com título igualmente profético: La prochaine peste. Nesse mesmo ano, David Quammen publicou Spillover. Animal Infections and the Next Human Pandemic. E em 28 de janeiro de 2020, Quammen publicou um artigo do The New York Time, cujo título não poderia ser mais contundente: "We Made the Coronavirus Epidemic". Haveria que lembrar ainda os trabalhos de Rob Wallace, mas decerto o mais fulminante veredito a respeito do caráter antropogênico diretamente derivado de nosso sistema alimentar carnívoro globalizado e de nosso sistema socioeconômico crescentemente disfuncional e destrutivo -, encontra-se no artigo de Josef Settele, Sandra Díaz, Eduardo Brondizio e Peter Daszak, escrito a convite do IPBES. 0 artigo inicia-se com o seguinte diagnóstico:

“Há uma única espécie responsável pela pandemia Covid-19: nós. Assim como com as crises climáticas e o declínio da biodiversidade, as pandemias recentes são uma consequência direta da atividade humana - particularmente de nosso sistema financeiro e econômico global baseado num paradigma limitado, que preza o crescimento econômico a qualquer custo. Temos uma pequena janela de oportunidade para superar os desafios da crise atual, de modo a evitar semear as sementes das crises futuras". 
Cada frase dessa citação encerra uma lição de ciência e de lucidez política. A pandemia em curso é, ao mesmo tempo, mais um elemento revelador, mais um alerta e mais um acelerador do processo em curso de colapso socioambiental.

REVISTA ECO-PÓS: Uma das questões que você pesquisa está ligada ao período geológico cunhado pelos biólogos Eugene F. Stoermer e Andrew C. Revkin como Antropoceno. Gostaríamos de ouvi-lo sobre alguns termos correlatos, como Capitaloceno (Jason Moore), Chthuluceno (Donna Haraway) e Plantationoceno (Tobias Menley).

Luiz Marques: 0 termo Capitaloceno apresenta a vantagem de ser mais explícito no que se refere ao motor a nos impelir para fora do Holoceno. De fato, não é o ser humano em geral, mas sua particular forma capitalista de organização social que nos levou ao Antropoceno e às crises que nos assediam. Mas essa e outras propostas não devem vingar. Antropoceno é o termo já consagrado, proposto há vinte anos para designar uma nova época geológica. Deve ainda ser ratificado pelas instâncias científicas com poder decisório sobre a nomenclatura estratigráfica, mas seu uso caiu de há muito na circulação sanguínea da sociedade, dentro e fora dos círculos científicos. Não se cogita seriamente substituí-lo por outro qualquer dentre os acima citados. 0 sufixo -ceno, comum a todas essas propostas, vem do adjetivo grego kainos, que significa novo ou recente, mas também, estranho, imprevisto, diverso do que se manifestara anteriormente etc. Aplicado a uma pessoa, ele designa um "alpinista social”, um parvenu, um Homo novus, na expressão latina. Podemos brincar com essa ambiguidade semântica e imaginar que o termo Antropoceno contenha também o significado, ou ao menos a conotação, de uma espécie nova e estranha aos velhos equilíbrios planetários, um parvenu com ridículas pretensões a ocupar uma posição que não lhe pertence no concerto da biosfera. Tornamo-nos muito rapidamente, de fato, uma espécie tão "estranha" aos equilíbrios biofísicos do sistema Terra, que há agora um risco real, crescente e mesmo iminente, de que esse sistema se torne terrivelmente inóspito à 
nossa espécie. Estamos tornando o planeta inabitável para nós próprios e nosso desparecimento é agora uma eventualidade crescentemente plausível. A extinção dos humanos seria, de um lado, um alívio para as outras espécies, mas, de outro, um empobrecimento enorme para o potencial cognitivo e espiritual da vida na Terra, porque o Homo sapiens não deve ser entendido apenas como um fracasso, como uma espécie singularmente agressiva, arrogante e estupidamente antropocêntrica. Nossa espécie é também dotada de faculdades incrivelmente positivas, a começar por sua enorme capacidade de abstração simbólica. Somos capazes de aprender a viver em paz com nós próprios e em relativo equilíbrio com a biosfera. Somos também dotados de senso moral, empatia, generosidade, altruísmo e senso estético. As outras espécies também são dotadas de tais faculdades, inclusive de senso estético. Mas a nossa é a única capaz de compor uma sinfonia, a única capaz de gerar um Michelangelo, um Beethoven, um Tolstói... Há uma proposta recente de conjugar o termo Antropoceno com o termo Piroceno, alusivo obviamente aos incêndios que se propagam por toda a parte. Conjugar, não substituir, porque enquanto o Antropoceno significa uma nova época geológica, o Piroceno designaria um novo período geológico, além do Quaternário (os últimos 2,58 milhões de anos), com seus típicos ciclos glacial-interglacial.

REVISTA ECO-PÓS: Nos últimos anos temos acompanhado o crescimento de certo discurso negacionista, que extrapola o aquecimento global e as mudanças climáticas. 0 que explica essa tendência? De onde é que vem isso?

Luiz Marques: Num artigo que publiquei ${ }^{1}$ na Folha de São Paulo no ano passado, tento discutir a questão do negacionismo. Claro que sua causa maior é a desinformação fomentada pelas corporações, como bem demonstrado no livro de Naomi Oreskes e Erik M. Conway, Merchants of Doubt: How a Handful of Scientists Obscured the Truth on Issues from Tobacco Smoke to Global Warming, de 2010. Mas ninguém engana reiteradamente

\footnotetext{
${ }^{1}$ N.E.: MARQUES, Luiz. Negação da ciência ganha força em nacionalismo que une esquerda e direita. São Paulo: Folha de São Paulo. Disponível em:

https://www1.folha.uol.com.br/ilustrissima/2019/01/negacao-da-ciencia-ganha-forca-emnacionalismo-que-une-esquerda-e-direita.shtml. Acesso em 16 nov. 2020.
} 
e por muito tempo quem não quer, de algum modo, ser enganado. É preciso entender que as mentiras dos mercenários da desinformação caem em ouvidos receptivos, porque as tristes verdades que a ciência está hoje gritando a plenos pulmões pelos telhados são, a cada dia que passa, mais e mais emocionalmente difíceis de ouvir. Segundo o The Crédit Suisse Global Wealth Report 2019, 89,2\% da população adulta do planeta divide apenas $17,3 \%$ da riqueza planetária. No outro extremo da pirâmide, 10,7\% dos adultos da humanidade detêm $82,7 \%$ da riqueza planetária. A ciência insta esse décimo da população adulta a sair de suas zonas de conforto, a rever suas premissas e seus paradigmas. Para muitos deles é preferível simplesmente negar frontal e puerilmente a ciência. Os negacionistas da emergência climática e da aniquilação da biodiversidade engrossam as fileiras dos terraplanistas, dos criacionistas, dos antivacinas, dos que negam a pandemia e as viagens de astronautas à lua, dos consumidores ávidos de fake \& hate news, dos conspiracionistas de todos os matizes, dos Q-Anon, por exemplo, que acabam de eleger dois deputados nos EUA. Há também os que não negam frontalmente a ciência, mas se agarram à crença de um "capitalismo verde". Para esses, os mercados e as corporações estariam se movendo no sentido de conformar suas atividades aos parâmetros biofísicos exigidos para conter o aquecimento global em níveis não catastróficos. Os fatos demonstram abundantemente o contrário, mas o que caracteriza o negacionismo é justamente sua impermeabilidade aos fatos ou sua notável capacidade de "adaptá-los" às suas convicções.

REVISTA ECO-PÓS: Em entrevista recente para o Instituto Humanitas (Unisinos) você afirma que "a palavra socialismo tem ainda sentido no século XXI se, e somente se, for entendida como ecossocialismo". O campo progressista ou a esquerda política tem incorporado a prática e o discurso ecológico? Nesse sentido, existem experiências a serem destacadas?

Luiz Marques: É claro que há progressos, mas são ainda demasiado lentos e insuficientes. É obviamente impossível atenuar o colapso socioambiental em curso se as decisões sobre os investimentos estratégicos, notadamente em energia, alimentação e 
mobilidade, permanecerem nas mãos das corporações. Mas isso não significa meramente transferir para o Estado o controle do capital privado. De resto essa transferência já está parcialmente consumada, por exemplo, no caso crucial da energia, pois as maiores corporações de petróleo e gás natural do mundo, por reservas e por renda, são estatais ou controladas por Estados. E estes agem e se pensam como corporações, subsidiam os fósseis, lucram e se financiam com eles, de modo que resistem tanto quanto o Big Oil privado à descarbonização da economia. Sim, a palavra socialismo tem ainda sentido no século XXI se, e somente se, for entendida como ecossocialismo. Resumo o que entendo por ecossocialismo em dois pontos e meu entendimento jamais perde de vista a nova, brutal e incontornável realidade de que o que hoje está em jogo não são mais as diversas agendas de progresso típicas dos séculos $\mathrm{XIX}$ e $\mathrm{XX}$, mas a viabilidade do projeto humano num mundo $2^{\circ} \mathrm{C}$ a $3^{\circ} \mathrm{C}$ em média mais quente que o período pré-industrial. Segundo as projeções mais conservadoras, esse nível de aquecimento será atingido no segundo ou terceiro quarto deste século, mantida a atual trajetória. 0 ecossocialismo significa, em primeiro lugar, redefinir o sentido mesmo da atividade econômica, que deve visar acima de tudo uma drástica redução do impacto antrópico sobre os equilíbrios do sistema Terra. Isso pressupõe, é claro, uma ordem jurídica diversa do capitalismo e uma democracia radical, que garanta à sociedade poder de veto a toda e qualquer tomada de decisão econômica incompatível com essa redefinição primeira. Em segundo lugar, é preciso entender o ecossocialismo como uma sociedade politicamente globalizada, isto é, livre da noção anacrônica e tipicamente militarista de soberania nacional absoluta. A governança global deve estar investida de poder mandatório no que se refere à descontinuação dos combustíveis fósseis, desmatamento zero e restauração florestal, poder este de natureza democrática, i.e., eleito por sufrágio universal e emancipado do poder de veto de instâncias como o Conselho de Segurança da ONU. Globalização política não significa fazer tabula rasa das peculiaridades culturais que fazem a riqueza da civilização humana. Significa, ao contrário, garantir-lhes o direito de permanecer à margem dos mercados homogeneizantes. Não é difícil entender que as crises trazidas pela globalização extrema do capitalismo são globais e só podem ser atacadas efetivamente pela 
globalização igualmente extrema da política. Nossa sobrevivência como sociedade organizada, talvez como espécie, depende de nossa capacidade de superar o horizonte mental da nação. Tudo isso é estranho ao horizonte ideológico e às práticas do socialismo do século XX e não teremos avançado nada se os partidos de esquerda acrescentarem o prefixo eco- ao socialismo apenas para parecerem mais "moderninhos". Esse prefixo não é um simples adjetivo do socialismo. Na realidade, o termo mais adequado para caracterizar uma sociedade mais apta à adaptação, frente ao sofrimento imenso que nos aguarda, seria socialecologismo, isto é, uma sociedade global fundada em seu comprometimento existencial com o que resta dos equilíbrios ecológicos do planeta, consciente de que esse comprometimento passa necessariamente pela superação do capitalismo e pela radical democratização da economia e da política.

REVISTA ECO-PÓS: A economia na América Latina tem uma ligação histórica com o extrativismo vegetal, mineral e animal. A partir do final da década de 1990 e início do século XXI, houve um crescimento exponencial dessas atividades, marcado pelo consenso de commodities, e que de certa forma perdura fortemente até os dias de hoje. $\mathrm{Na}$ sua opinião, o Brasil está cada vez mais dependente dessa condição de país exportador de bens primários (como é o caso da mineração, do petróleo, da soja e da carne)?

Luiz Marques: Não é uma questão de opinião. É um fato confortado pela totalidade dos indicadores históricos e econômicos. 0 Brasil é o exemplo extremo de uma economia agro-mínero-exportadora, insustentável não apenas em termos ecológicos, mas também em termos estritamente econômicos. Quem pode crer que uma economia sobreviva graças à exportação de minérios, carne e ração animal para porcos, frangos e peixes situados a muitos milhares de quilômetros de distância? O Brasil é uma costela do sistema alimentar mundial e este é o aspecto mais vulnerável do capitalismo globalizado, pois diretamente dependente de condições climáticas favoráveis e de oferta de petróleo barato para o transporte e para a fabricação de fertilizantes industriais. Há incerteza quanto ao futuro do petróleo barato, mas absoluta certeza de que os riscos 
climáticos diminuirão a produtividade agrícola até o ponto de inviabilizar o agronegócio. Mesmo que isso não ocorra de imediato, quem pode acreditar que o próprio país sobreviva, quando sua arquitetura econômica supõe dizimar seus povos originários, derrubar e incendiar suas florestas, destruir suas paisagens naturais, sua fauna, sua flora e seus solos, intoxicar a população humana e a de outros animais com quantidades crescentes de agrotóxicos, jogar mercúrio em seus rios e esgotar seus recursos hídricos? Os trágicos 21 anos da ditadura militar colocaram o Brasil em situação ecológica de alto risco. Esse risco só aumentou com os governos do PSDB e do PT, malgrado o breve interregno de notável diminuição do desmatamento amazônico entre os anos 2005 e 2012. Com Dilma e Temer, a curva tornou-se novamente ascendente. Com apenas dois anos de Bolsonaro, a devastação do país, e não apenas de suas florestas, atingiu tais proporções que, admitamos sem mais rodeios, é altíssima a probabilidade de que a economia brasileira já tenha se tornado francamente inviável. Sem florestas, sem chuvas, com seus polinizadores dizimados por agrotóxicos, sujeito a secas, inundações e picos de calor cada vez frequentes e maiores, o Brasil pode começar a ter a qualquer momento quebras recorrentes de safra, e/ou uma gripe aviária, com ondas de impacto em toda a sua economia. Isso não é uma conjectura. É uma probabilidade que aumenta ano a ano, decorrente da destruição pelo desmatamento e pelas chamas da Amazônia, do Cerrado, da Caatinga, do Pantanal e dos resquícios da Mata Atlântica, com desdobramentos fatais inclusive para o Sul e o Sudeste do país. Em plena terceira semana de novembro, o nível do sistema Cantareira continua baixando e está agora reduzido a cerca de $32 \%$ de sua capacidade acima do volume morto. Estamos novamente sujeitos a recair, de uma hora para outra, numa crise hídrica igual ou pior que a de 2014. Os meses em que as chuvas são menores ou muito menores que as médias históricas são mais numerosos do que os meses em que elas atingem ou superam essas médias. Dado que o desmatamento continua por toda a parte, inclusive na Mata Atlântica, e dado que sem florestas não há chuva, é apenas questão de tempo até atingirmos níveis críticos dos sistemas de abastecimento hídrico em nossa região, isso para não falar nos impactos sobre a oferta de energia hidrelétrica. 
REVISTA ECO-PÓS: É possível falar em Decrescimento no contexto nacional ou mesmo continental?

Luiz Marques: Depende do significado atribuído à palavra decrescimento. Como dito acima, o decrescimento, entendido como crescimento negativo do PIB, não é uma escolha, não é apenas uma possibilidade, é uma tendência inexorável ao longo da década que se abre em 2021, e talvez mesmo já a partir de 2021, mesmo sem a pandemia. Se, por outro lado, decrescer significa algo que nada tem a ver com métricas como o PIB e outros dogmas religiosos, se decrescer significa diminuir o impacto da atividade econômica sobre a biosfera e sobre o sistema Terra em geral, então decrescer não é apenas possível, mas é algo absolutamente imprescindível para nossa sobrevivência.

REVISTA ECO-PÓS: Você foi curador-chefe do MASP (Museu de Arte de São Paulo) na década de 1990. E também já publicou livros e artigos sobre história da arte. 0 interesse aqui é saber como as duas facetas das suas pesquisas podem se conectar. De que forma os artistas e suas obras abordam o colapso ambiental?

Luiz Marques: Até onde alcança minha imaginação, não vislumbro qualquer conexão entre a história da arte italiana dos séculos XIII a XVI, que estudei durante a maior parte da minha vida estudantil e docente, e a observação de processos de colapso socioambiental. O Renascimento se interessou apaixonadamente, como é de todos sabido, pelo legado da civilização greco-romana, pela questão, portanto, da descontinuidade histórica, o que inclui uma intensa reflexão sobre a questão geral do colapso civilizacional. Essa reflexão está presente em Maquiavel e Guicciardini, leitores atentos, por exemplo, de Políbio e Plutarco. Está presente também em artistas como Rafael e Vasari, autores de reflexões pioneiras sobre a historicidade da arte antiga. Mas em todos esses casos a reflexão se ocupa de declínios e colapsos históricos, não socioambientais. É apenas desde a Revolução Industrial que a questão dos impactos humanos sobre a natureza, sobre catástrofes ocorrendo no nível da biosfera, começou a sensibilizar os artistas. Um pintor fascinante nesse contexto é John Martin (1789-1854), autor de obras de grandes dimensões, nas quais imaginações fulgurantes do Apocalipse 
e do Juízo Final são quase pretextos para a figuração delirante de cataclismos naturais, para não dizer cósmicos. Como não poderia deixar de ser, o colapso socioambiental em curso é um tema que tem atraído cada vez mais a atenção, a preocupação e a sensibilidade dos artistas contemporâneos. Mas não saberia avaliar, a não ser como um observador casual, as abordagens desses artistas. 